Original Article

\title{
The effects of lumbar stabilization exercise with thoracic extension exercise on lumbosacral alignment and the low back pain disability index in patients with chronic low back pain
}

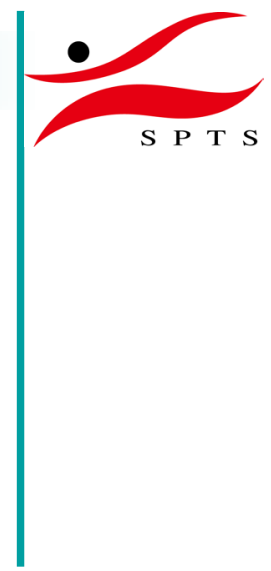

\author{
Seong-Dae Woo, MS, PT ${ }^{1)}$, TAe-Ho Kim, PhD, $\mathrm{PT}^{1)^{*}}$ \\ 1) Department of Physical Therapy, College of Rehabilitation Science, Daegu University: 15 Jillyang, \\ Gyeongsan-si, Gyeongsangbuk-do 712-714, Republic of Korea
}

\begin{abstract}
Purpose] To determine the effects of lumbar stabilization exercise with thoracic extension exercise on chronic low back pain patients. [Subjects and Methods] Thirty patients with chronic low back pain were randomly divided into a lumbar stabilization exercise group (group A) and a lumbar stabilization exercise with thoracic extension exercise group (group B). Group B did 15 min of lumbar stabilization exercises and 15 min of thoracic extension exercises, while group A did 30 min of lumbar stabilization exercises five times a week for 4 weeks. For assessing lumbosacral alignment, the lordotic angle, lumbosacral angle, and sacral angle were evaluated. The Oswestry disability index was used for assessment of disability due to low back pain. [Results] Both groups showed improvement in lumbosacral alignment and in the disability index. Group B showed greater changes in the lordotic angle and in the Oswestry disability index than group A, although the differences were not statistically significant. [Conclusion] Lumbar stabilization exercise with thoracic extension exercise can be recommended for improvement of chronic low back pain, although the improvements seen in lumbosacral alignment and low back pain disability index in this study did not achieve statistical significance.

Key words: Lumbar stabilization exercise, Thoracic extension exercise, Lumbosacral alignment
\end{abstract}

(This article was submitted Oct. 26, 2015, and was accepted Nov. 19, 2015)

\section{INTRODUCTION}

Low back pain is one of the most widespread disorders in modern societies. It can limit the daily activities of patients, and the cost of management can be considerable ${ }^{1)}$. The causes of low back pain are varied and complex, should be dealt with from various viewpoints ${ }^{2}$. Socioenvironmental factors as well as personal constitution and habits can all play a part in the etiology of low back pain ${ }^{3}$. In recent studies, low back pain has been shown to be caused by weakness of the deep muscles of the lumbar region, reduction in postural sense and kinesthetic ability due to imbalance, and reduced proprioceptive sense. These factors result in an unstable spine and lead to recurrence of low back pain ${ }^{4}$. Bae et al. ${ }^{5)}$ reported that exercise on an unstable surface was better for enhancing the size of the trunk muscles and improving balance ability than exercise on a stable surface. Selective exercises for the deep abdominal muscles and lumbar stabilization exercises could thicken the transversus abdominis, which is a deep abdominal muscle, and thereby help in adjusting posture and stabilizing the trunk ${ }^{6}$.

Chronic low back pain can cause postural problems due to pelvic torsion and lumbar lordosis, both of which lead to repeated attacks of low back pain ${ }^{7}$. Disorder of proprioceptive sensibility has been reported to occur due to incorrect alignment ${ }^{8,9}$. Poor proprioceptive sensibility and somesthesia, as well as diminished vision, combine to cause disorder of balance control $^{10)}$. Recent studies on the treatment of low back pain have focused on the stabilization provided by strengthening of

\footnotetext{
*Corresponding author. Tae-Ho Kim (E-mail: ptkimth@daegu.ac.kr)

(C)2016 The Society of Physical Therapy Science. Published by IPEC Inc.

This is an open-access article distributed under the terms of the Creative Commons Attribution Non-Commercial No Derivatives (by-nc-nd) License $<$ http://creativecommons.org/licenses/by-nc-nd/4.0/>.
} 
the deep muscles in the lumbar spine and pelvis. Trunk movement patterns can be altered by changing trunk muscle activities or lengths ${ }^{11)}$. The current study aimed to determine the effects of thoracic extension exercise in improving lumbosacral alignment and relieving low back pain.

\section{SUBJECTS AND METHODS}

This double-blind, randomized clinical trial was conducted with 30 patients who were admitted to a clinic inside $\mathrm{H}$ Company or a physiotherapy clinic in H Hospital for complaints of low back pain for more than 3 months. All participants gave written informed consent for inclusion in the study. The subjects were divided into a lumbar stabilization exercise group (group A; $\mathrm{n}=15$ ) and a lumbar stabilization exercise with thoracic extension exercise group (group B; $\mathrm{n}=15$ ). The mean age, mean height, and mean weight in group A were 39.8 years, $165.5 \mathrm{~cm}$, and $64.9 \mathrm{~kg}$, respectively vs 40.1 years, $165.8 \mathrm{~cm}$, and $64.5 \mathrm{~kg}$, respectively, in group B; these differences were not statistically significant.

Each group performed their respective exercises regularly for 4 weeks. The changes in the lumbosacral alignment and low back pain disability index (Oswestry disability index; ODI $)^{12,13)}$ were measured and compared between the groups after the intervention as well as within the groups before and after the intervention. The lumbar stabilization exercise consisted of previously studied exercises ${ }^{14-18)}$; the exercise methods proposed by Hur et al. ${ }^{19)}$ were referred to as the thoracic extension exercise. In both groups, the exercise program began with a 5-min warm-up session of stretching; this was followed by $30 \mathrm{~min}$ of stabilization exercises and thoracic extension exercise, and ended with a 5-min cool-down session (Table 1).

To assess lumbosacral alignment, lateral radiographs of the lumbosacral spine in the standing position were taken; all radiographs were taken by the same radiographer. Many methods have been used to measure lumbosacral alignment. In this study, we used the method proposed by Wiltse et al., which uses the lordotic angle (LA), lumbosacral angle (LSA), and sacral

Table 1. Lumbar stabilization exercise and thoracic extension exercise program

\begin{tabular}{lll}
\hline \multicolumn{1}{c}{ Type } & \multicolumn{1}{c}{ Program } & \multicolumn{1}{c}{ Time taken } \\
\hline Warm-up exercise & General stretching & min \\
\hline Lumbar stabilization exercise & 1. Lower extremity lifting in a bridge posture & Group A; $30 \mathrm{~min}$ \\
& 3. Lower extremity lift in a prone position on a ball & $(10-12$ times $\times 4$ sets $)$ \\
& 4. Upper extremity lift in a prone position on a ball & Exercise time per set \\
& 5. Moving the body forward grasping a sling in a kneeling position & $(30-40 \mathrm{~s})$ \\
& 6. Lifting the buttocks with the lower extremity hooked on a sling & Group B; $15 \mathrm{~min}$ \\
& in a supine position & $(10-12$ times $\times 2$ sets $)$ \\
& & Exercise time per set \\
& & $(30-40 \mathrm{~s})$ \\
\hline Thoracic extension exercise & Fig. 1. & Group B; 15 min \\
& & $(10-12$ times $\times 2$ sets $)$ \\
& & Exercise time per set \\
& & $(30-40 \mathrm{~s})$ \\
\hline Cool-down exercise & General stretching & 5 min \\
\hline Total & & 40 min \\
\hline
\end{tabular}

Group B: Lumbar stabilization exercise with thoracic extension exercise group; Group A: Lumbar stabilization exercise group

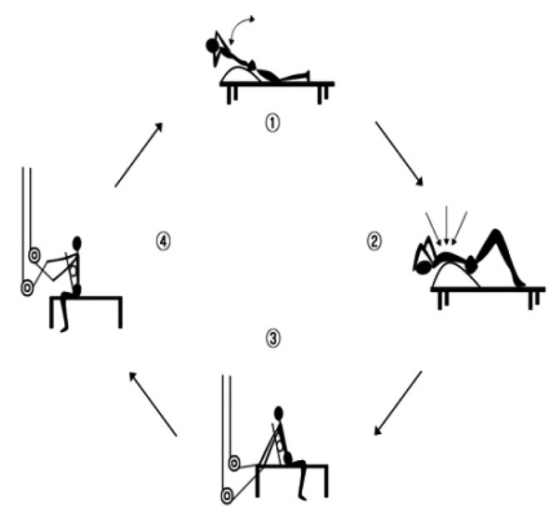

Fig. 1. Thoracic extension exercise 
angle (SA) for measuring changes in lumbosacral alignment ${ }^{20)}$. The ODI was used to evaluate disability due to low back pain.

The independent $t$ test was used to perform a homogeneity analysis between the groups before and after the intervention and the paired $t$ test was used to analyze the changes in the variables before and after exercise. PASW for Windows (ver. 18.0) was used for the statistical analysis. The significance level (p) was set to 0.05 .

\section{RESULTS}

In the within-group comparison of the variables before and after the intervention, both groups showed significant increases in LA, LSA, SA, and ODI after 4 weeks of exercise $(p<0.05$; Table 2).

There were no significant differences between the groups before the intervention. After the intervention, group B showed greater increase in LA and less decrease in LSA, SA, and ODI than group A; however, the differences were not statistically significant (Table 3).

\section{DISCUSSION}

The lumbosacral region in the spine experiences large applied momentum. The region is not stable and therefore the ligaments, muscles, and joints in the region are prone to injury because of incorrect posture, trauma, and disease. Many structural changes in alignment can occur, which are closely related to low back pain ${ }^{21)}$. The relationship between lumbar lordosis and low back pain has been a controversial for a long time, and researchers have reported different conclusions. Some researchers have said that low back pain is related to increase in lumbar lordosis ${ }^{7}$, whereas others have claimed that low back pain is related to decreases in lumbar lordosis ${ }^{22}$. One study has found no correlation between low back pain and lumbar lordosis ${ }^{23)}$. In this study, significant increase in LA was seen in both exercise groups: from $26.01^{\circ}$ to $26.99^{\circ}$ in group A and from $24.27^{\circ}$ to $28.02^{\circ}$ in group B. After the intervention, there was no significant difference in LA between the two groups; however, the increase was much greater in group B ( $3.75^{\circ}$ in group B vs. $0.98^{\circ}$ in group A). This result is consistent with previous studies

Table 2. Lumbosacral alignment and ODI index pre- and postintervention $(\mathrm{N}=30)$

\begin{tabular}{lccc}
\hline Variable & Group & $\begin{array}{c}\text { Preintervention } \\
(\text { mean } \pm \text { SD) }\end{array}$ & $\begin{array}{c}\text { Postintervention } \\
(\text { mean } \pm \text { SD) }\end{array}$ \\
\hline \multirow{2}{*}{ Lordotic angle $\left(^{\circ}\right)$} & Group B* & $24.3 \pm 4.9$ & $28.0 \pm 3.5$ \\
& Group A* & $26.0 \pm 7.0$ & $27.0 \pm 6.7$ \\
\hline \multirow{2}{*}{ Lumbosacral angle $\left(^{\circ}\right)$} & Group B* & $17.1 \pm 4.0$ & $15.1 \pm 3.1$ \\
& Group A* & $15.7 \pm 4.7$ & $13.5 \pm 3.4$ \\
\hline \multirow{2}{*}{ Sacral angle $\left(^{\circ}\right)$} & Group B* & $37.2 \pm 5.0$ & $33.8 \pm 2.7$ \\
& Group A* & $34.1 \pm 6.3$ & $31.3 \pm 4.3$ \\
\hline \multirow{2}{*}{ ODI $(\%)$} & Group B* & $40.4 \pm 9.4$ & $23.0 \pm 6.0$ \\
\hline
\end{tabular}

${ }^{*} \mathrm{p}<0.05$

Group B: lumbar stabilization exercise with thoracic extension exercise group; Group A: lumbar stabilization exercise group

Table 3. Comparison between the groups pre- and postintervention $(\mathrm{N}=30)$

\begin{tabular}{llcc}
\hline \multirow{2}{*}{ Variables } & \multicolumn{1}{c}{ Stage } & $\begin{array}{c}\text { Group B } \\
(\text { mean } \pm \text { SD })\end{array}$ & $\begin{array}{c}\text { Group A } \\
(\text { mean } \pm \text { SD) }\end{array}$ \\
\hline \multirow{2}{*}{ Lordotic angle $\left(^{\circ}\right)$} & Preintervention & $24.3 \pm 4.9$ & $26.0 \pm 7.0$ \\
& Postintervention & $28.0 \pm 3.5$ & $27.0 \pm 6.7$ \\
\hline \multirow{2}{*}{ Lumbosacral angle $\left(^{\circ}\right)$} & Preintervention & $17.1 \pm 4.0$ & $15.7 \pm 4.7$ \\
& Postintervention & $15.1 \pm 3.1$ & $13.5 \pm 3.4$ \\
\hline \multirow{2}{*}{ Sacral angle $\left(^{\circ}\right)$} & Preintervention & $37.2 \pm 5.0$ & $34.1 \pm 6.3$ \\
& Postintervention & $33.8 \pm 2.7$ & $31.3 \pm 4.3$ \\
\hline \multirow{2}{*}{ ODI $(\%)$} & Preintervention & $40.4 \pm 9.4$ & $36.7 \pm 5.4$ \\
\hline
\end{tabular}

Group B: lumbar stabilization exercise with thoracic extension exercise group;

Group A: lumbar stabilization exercise group 
where normal people had larger increases in lumbar lordosis than patients with low back pain ${ }^{21,24)}$. Other studies have suggested that thoracic curves are affected by weight load and motion types, and that the greater the thoracic stiffness, the more movements there are in the lumbar and cervical spine because of a compensatory action, which is a mechanical change in the thoracic vertebral region morphologically ${ }^{25}$. A previous study has reported that as age increases, women tend to develop more severe lumbar lordosis than $\operatorname{men}^{26}$. A study on growing children and adolescents also found that the lumbar lordotic angle increased from $25^{\circ}$ at age 7 to $38^{\circ}$ at age 19 - an increase of $0.58^{\circ}$ every year ${ }^{27}$. The lumbar lordosis that develops with age involves more of the upper lumbar vertebrae ${ }^{28)}$. The present study showed that thoracic extension exercise affected the recovery of lumbar lordosis, which was curved in the upper lumbar vertebrae.

One study has reported that patients with low back pain have greater SAs than normal persons ${ }^{29}$ ). In the present study, the SA decreased from $34.08^{\circ}$ to $31.25^{\circ}$ in group A and from $37.25^{\circ}$ to $33.81^{\circ}$ in group $\mathrm{B}$, which is consistent with previous findings. The recovery of the normal sacrum range because of the lumbar stabilization exercise, and the recovery of the upper lumbar lordosis because of the thoracic extension exercise, reduced the sacrum's excessive inclination.

Many previous studies have reported reduction in the ODI after lumbar stabilization exercises ${ }^{30,31)}$. In the present study, both groups had significant reductions in ODI: from $36.74 \%$ to $23.85 \%$ in group A and from $40.44 \%$ to $22.96 \%$ in group B. No significant difference was found between the two groups after 4 weeks of exercise, but the change in ODI was greater in group B than in group A (17.48\% in group B vs. $12.89 \%$ in group A).

This study has some limitations. The intervention duration was rather short at 4 weeks. Earlier studies have used different methods to measure the lumbosacral region, so there were large differences in the measured angles in terms of comparison and analysis. In a future study, we intend to measure changes in the thoracic kyphosis angle after thoracic extension exercise and analyze changes in the segmental angles in the upper lumbar vertebrae.

\section{REFERENCES}

1) O'Sullivan PB: Lumbar segmental 'instability': clinical presentation and specific stabilizing exercise management. Man Ther, 2000, 5: 2-12. [Medline] [CrossRef]

2) Graves JE, Webb DC, Pollock ML, et al.: Pelvic stabilization during resistance training: its effect on the development of lumbar extension strength. Arch Phys Med Rehabil, 1994, 75: 210-215. [Medline]

3) Risch SV, Norvell NK, Pollock ML, et al.: Lumbar strengthening in chronic low back pain patients. Physiologic and psychological benefits. Spine, 1993, 18: 232-238. [Medline] [CrossRef]

4) O'Sullivan PB, Burnett A, Floyd AN, et al.: Lumbar repositioning deficit in a specific low back pain population. Spine, 2003, 28: 1074-1079. [Medline] [CrossRef]

5) Bae SH, Lee HG, Kim YE, et al.: Effects of trunk stabilization exercises on different support surfaces on the crosssectional area of the trunk muscles and balance ability. J Phys Ther Sci, 2013, 25: 741-745. [Medline] [CrossRef]

6) Lee JS, Kim TH, Kim DY, et al.: Effects of selective exercise for the deep abdominal muscles and lumbar stabilization exercise on the thickness of the transversus abdominis and postural maintenance. J Phys Ther Sci, 2015, 27: 367-370. [Medline] [CrossRef]

7) Christie HJ, Kumar S, Warren SA: Postural aberrations in low back pain. Arch Phys Med Rehabil, 1995, 76: $218-224$. [Medline] [CrossRef]

8) Descarreaux M, Blouin JS, Teasdale N: Repositioning accuracy and movement parameters in low back pain subjects and healthy control subjects. Eur Spine J, 2005, 14: 185-191. [Medline] [CrossRef]

9) Dolan KJ, Green A: Lumbar spine reposition sense: the effect of a 'slouched' posture. Man Ther, 2006, 11: 202-207. [Medline] [CrossRef]

10) Brumagne S, Cordo P, Verschueren S: Proprioceptive weighting changes in persons with low back pain and elderly persons during upright standing. Neurosci Lett, 2004, 366: 63-66. [Medline] [CrossRef]

11) Kavcic N, Grenier S, McGill SM: Quantifying tissue loads and spine stability while performing commonly prescribed low back stabilization exercises. Spine, 2004, 29: 2319-2329. [Medline] [CrossRef]

12) Sakulsriprasert $P$, Vachalathiti R, Vongsirinavarat M, et al.: Cross-cultural adaptation of modified Oswestry Low Back Pain Disability Questionnaire to Thai and its reliability. J Med Assoc Thai, 2006, 89: 1694-1701. [Medline]

13) Fairbank JC, Pynsent PB: Oswestry disability index. Spine, 2000, 25: 2940-2952, discussion 2952. [Medline] [CrossRef]

14) Yoo WG: Comparison of the isolated contraction ratios of the hip extensors and erector spinae muscles of the lumbar region and thoracic muscles during different back extension exercises. J Phys Ther Sci, 2015, 27: 315-316. [Medline] [CrossRef] 
15) Lehman GJ, Hoda W, Oliver S: Trunk muscle activity during bridging exercises on and off a Swiss ball. Chiropr Osteopat, 2005, 13: 14. [Medline] [CrossRef]

16) Marshall P, Murphy B: Changes in muscle activity and perceived exertion during exercises performed on a swiss ball. Appl Physiol Nutr Metab, 2006, 31: 376-383. [Medline] [CrossRef]

17) McGill SM, Karpowicz A: Exercises for spine stabilization: motion/motor patterns, stability progressions, and clinical technique. Arch Phys Med Rehabil, 2009, 90: 118-126. [Medline] [CrossRef]

18) Stevens VK, Bouche KG, Mahieu NN, et al.: Trunk muscle activity in healthy subjects during bridging stabilization exercises. BMC Musculoskelet Disord, 2006, 7: 75. [Medline] [CrossRef]

19) Hur JG, Song JC, No YM, et al.: Effect on active exercise programs in employees with chronic low back pain. Korean J Occup Environ Med, 2005, 17: 44-57.

20) Wiltse LL, Winter RB: Terminology and measurement of spondylolisthesis. J Bone Joint Surg Am, 1983, 65: 768-772. [Medline]

21) Jackson RP, McManus AC: Radiographic analysis of sagittal plane alignment and balance in standing volunteers and patients with low back pain matched for age, sex, and size. A prospective controlled clinical study. Spine, 1994, 19: 1611-1618. [Medline] [CrossRef]

22) Tsuji T, Matsuyama Y, Sato K, et al.: Epidemiology of low back pain in the elderly: correlation with lumbar lordosis. J Orthop Sci, 2001, 6: 307-311. [Medline] [CrossRef]

23) Tüzün C, Yorulmaz I, Cindaş A, et al.: Low back pain and posture. Clin Rheumatol, 1999, 18: 308-312. [Medline] [CrossRef]

24) Kim BG, Park RJ, Lee SJ: Difference of lumbar lordosis in patients with low back pain and controls. J Kor Soc Phys Ther, 2000, 12: 185-190.

25) Edmondston SJ, Singer KP: Thoracic spine: anatomical and biomechanical considerations for manual therapy. Man Ther, 1997, 2: 132-143. [Medline] [CrossRef]

26) Fon GT, Pitt MJ, Thies AC Jr: Thoracic kyphosis: range in normal subjects. AJR Am J Roentgenol, 1980, 134: $979-983$. [Medline] [CrossRef]

27) Giglio CA, Volpon JB: Development and evaluation of thoracic kyphosis and lumbar lordosis during growth. J Child Orthop, 2007, 1: 187-193. [Medline] [CrossRef]

28) Suk SL, Lee CS, Lo M, et al.: Normal segmental sagittal angle of the lower dorsal and lumbosacral spine in Korean adult. J Korean Orthop Assoc, 1989, 24: 237-244.

29) Korovessis P, Stamatakis M, Baikousis A: Segmental roentgenographic analysis of vertebral inclination on sagittal plane in asymptomatic versus chronic low back pain patients. J Spinal Disord, 1999, 12: 131-137. [Medline]

30) Hicks GE, Fritz JM, Delitto A, et al.: Preliminary development of a clinical prediction rule for determining which patients with low back pain will respond to a stabilization exercise program. Arch Phys Med Rehabil, 2005, 86: 17531762. [Medline] [CrossRef]

31) Ferreira PH, Ferreira ML, Maher CG, et al.: Changes in recruitment of transversus abdominis correlate with disability in people with chronic low back pain. Br J Sports Med, 2010, 44: 1166-1172. [Medline] [CrossRef] 